\title{
The Functions of Teacher's Professional Virtue in Teaching
}

\author{
Bayi Guan \\ Yantai Nanshan University \\ Yantai, Shandong, China 265713
}

\author{
Zhanli Shang \\ Yantai Nanshan University \\ Yantai, Shandong, China 265713
}

\author{
Hongwei Zhao \\ Nanshan Finance Company Ltd. \\ Yantai, Shandong, China 265706
}

\begin{abstract}
Teachers are the professionals who perform the responsibilities of education and teaching, undertaking the mission of teaching, cultivating the builders of this society, and enhancing the national quality. Teachers should not only have profound knowledge but also shall have good virtue. Teachers are the first resource of education, the large number of excellent students cannot be cultivated without good teaching staff. The reasonable and effective development of course resources is the teachers' professional virtue, which is beneficial to students' healthy growth and development, the realization of teaching goals and the social needs and development.
\end{abstract} role

Keywords-teachers; professional virtue; teaching; course;

\section{INTRODUCTION}

"It takes ten years to grow trees, but a hundred to cultivate people". Thus it can be seen the role of teachers in education industry. Teachers have a lifetime influence on students, but have a far-reaching impact on the state. Since the ancient times, from the "strict teacher" to "famous teacher" to today's "excellent teacher", all have the same region in terms of the development and innovation spirit although the title is a bit different. Teachers' virtue influences the development of students, but influences the state's construction in each phase of the society.

\section{INTERPRETATION OF THE CONNOTATION OF TEACHERS' PROFESSIONAL VIRTUE}

Teachers are the professionals who perform the responsibilities of education and teaching, undertaking the mission of teaching, cultivating the builders of this society, and enhancing the national quality. Teachers should not only have profound knowledge but also shall have good virtue. Teachers' influence on the lifetime development of students is a directional milestone. Teachers influence students in the cultivation of their outlook on life and world view profoundly yet with rich futurity. Teachers' virtue is the positive influence on certain society development by teaching profession, which is the foundation for the teachers to be respected by the society and human. Teachers' professional virtue plays a huge role on the development of society. First, teachers are responsible for the transmission of human culture, playing the essential role in the process of human society development; second, teachers are the creators of social material wealth and spiritual wealth, and they are directly involved in the construction of social material civilization and spiritual civilization through certain theoretical construction, knowledge innovation, moral demonstration, publicity and consultation, playing a role of guidance; third, teachers are the main undertakers of talent cultivation, shouldering on the responsibility of cultivation of the new generation, playing a role of guidance on students' development. Therefore, teachers' professional virtue plays huge role, and teachers' work should be recognized and respected by all the people.

British philosopher Bacon once regarded teachers as "the spreader of scientific knowledge, the cultivator of civilization, and the designer of human soul". Modern education is different from that of the past, as the past education is primarily a scientific education to cultivate humanistic knowledge, which is indifferent of the technological development and innovation; and modern education not only pays attention to the development of humanistic knowledge, but also lays emphasis on the cultivation of human civilization of science and technology, they have a harmonious development and complement each other. "Teacher" in the modern sense is different from the "teacher" in ancient sense essentially: first is the versatility; second is specialty, teacher must be cultivated and trained, and get the certificate of qualification; the third one is high quality, modern teachers have more abundant connotation as the unity of "Confucian classics teachers" and "human teachers"; the forth one is developmental, modern teachers must perform lifelong learning to constantly update their knowledge structure and ability structure, making themselves understand how to learn. ${ }^{[1]}$

Building the harmonious socialist society is the major strategic task which has been proposed from the overall arrangements of socialism with Chinese characteristics and the overall situation of building a well-off society in an all-round way, reflecting the inner requirements of building a prosperous, democratic, civilized and harmonious modern socialist country, 
indicating the common aspiration of the whole Party and the people of all ethnic groups. To achieve social harmony, it needs the strong material base and reliable political guarantee as well as powerful spiritual support and good cultural conditions. Harmonious culture takes advocating and pursuing harmony as the value orientation, integrating ideological concept, way of thinking, behavior standard and social customs as a whole, reflecting people's overall understanding, basic concept and ideal pursue toward harmonious society, being an important part of advanced socialist culture. The support of harmonious culture is inseparable for the coordinated development of both economy and society, the harmony between human and nature, and the unity between people and even the human's own psychological harmony. Therefore, building a harmonious culture is the important content and basic work for constructing a harmonious society, which is conducive to consolidate the ideological basis of social harmony, contributes to the cultivation of ideology and the thinking way of coordinated development, and is helpful to resolve social contradictions. Building a harmonious socialist society not only has the internal need of but will also produce the corresponding harmonious culture. "Teachers are the engineers of human soul," [2] and teachers' professional virtue plays an important role of appealing and inheritance in terms of cultivating powerful spiritual civilization support and creating the profound cultural conditions.

\section{DEVElopment OF TEACHER RESOURCES}

Teachers are the primary resource of the education, and the large number of excellent students cannot be cultivated without good teaching staff. "Teachers are responsible for preaching, teaching and answering questions." An excellent teacher is important for students' development, and is very effective to reasonably develop the resources of the teachers themselves. The rich ways of thinking, psychological quality, value idea, education thought, knowledge accomplishment, the education and teaching techniques, etc of the teachers all can made to be the curriculum resources. ${ }^{[1]}$ Teachers must carefully study the teaching practice and make the teaching reflection in order to develop the course resources practically. Results of teaching reflection is the potential course resources, which upgrades to theory from the direct experience in teaching, and in turn, it directly influences the teaching practice. ${ }^{[2]}$ Teachers must carry on teaching research, of which the process is also the process of course development. They should deal with the teaching materials very well; translate the teaching material of resources for activity, and break through the constraint of teaching materials, to really make the teaching materials to be targeted at the students. Make a good use of the teaching material flexibly, to add value to the text resources of teaching material. Teachers should constantly improve and change the teaching material contents, and blend in professional practice and innovation of new technology. The role of teachers in course resource development is the same as the development of mineral resources, having both the role of exploration and the responsibility of reasonable choice. The reasonableness of course resources plays an important role on the teaching quality and cultivation effect to a large extent.
Teacher resources shall be developed reasonably starting from acknowledging teachers' social function, improving the political status of teaching profession, enhancing the economic treatment of teaching profession, respecting the rights of teaching profession and regulating the professional standards of teaching profession. Only by positively developing teachers' various potential resources and mobilize their enthusiasm, can the teachers' talents be given full play and mutual encouragement between students and teacher be reflected. The teaching profession is a profession with teaching as the responsibility, and cultivating talents purposefully is fundamental characteristic that education is different from other social fields. The work of educating is completed by the mutual coordination of many aspects, and teaching profession conducts education through teaching. The so called teaching refers to teachers teach the systematic scientific and cultural knowledge to the students, and guide students to establish the scientific world view and view of life, instruct the students to learn positively and effectively, and create a good teaching atmosphere to promote students' healthy and rapid growth by undertaking the teaching of various courses. Teaching and education are the two aspects of the same process, reflecting the essence of teaching profession. ${ }^{[3]}$

\section{IV.TEACHERS' PROFESSION VIRTUE AND COURSE RESOURCE DEVELOPMENT}

Teachers are the main body for development of course resources, who conduct curriculum design and resources development through reasonable analysis and positioning of teaching process, teaching group, teaching purpose and teaching effect. The reasonable and effective development of course resources is teachers' professional virtue, which is beneficial to students' healthy growth and development, contributes to the realization of teaching goals, and is advantageous to the social needs and development. Course resources refer to the total manpower, material and natural resources in the process of designing, implementing and evaluating of the whole course. ${ }^{[1]}$ The practical significance of teachers' mastery and effective development of course resources is to link theory with practice, and complete the inheritance and innovation of knowledge.

Teachers' professional virtue is embodied in the aspect of course resources and is reflected as to develop course resources actively and effectively. In a broad sense, course resources have the same meaning with teaching resources, referring to the source of course and teaching information, namely various material, spiritual and manpower factors with education value and can be incorporated into the curriculum system and is conducive to the realization of curriculum and teaching target. ${ }^{[2]}$ The interpretation of course resources have taken the implicit and potential resources into consideration, made clear the functions of different types of resources, having the important guiding significance to the development. But this understanding is the discussion on course resource in terms of courses, without highlighting the value orientation of course resources and establishing close relationship with learning. From the perspective of cultural philosophy, course is a special kind of culture, and development of course research is the operation of learning process. Course resources are the various 
factors and implement condition that influence learning, life existence and its optimization activities, which is the support system of study, to support generation and development of learning activities. Course resources indicate their existence value through servicing learning. ${ }^{[3]}$

The key for course resource definition lies in whether it contains course potential (or called course possibility), that is to say that course resources must be able to serve the course and course implementation, which is conducive to the realization of course goal. Course resource is an important part of education resources, the source of such structural elements as course systematic material, energy and information, the content system and activity supporting system which contains rich course potential in the process of course implementation, and the support and guarantee for the effective development of course implementation. Course resources are the broad social resources with rich course potential and exist objectively, having a very close relationship with the courses; its position and role in course existence and implementation is very important, being the courses' internal constituent elements and operating conditions, providing continuously the necessary material, energy and information to the courses and course implementation, which is a solid foundation and important guarantee for the course and its implementation. ${ }^{[4]}$

Course resources not only have the value of course, but also have the rich connotation of psychology.

- Course resources is the carrier of knowledge, besides the traditional resource of books, it also includes such resources with modern characteristics as recording, video recording technology and network, as well as the human resources represented by teachers. The symbol system carried by these resources is knowledge, which is the object to be learned by the students.

- Course resource is the medium of teaching, which shall include the spiritual resources such as students' cognitive ability and experience which acts as a medium for course implementation.

- Course resources form the factors of teaching environment, as the reasonable combination of course resources form the environment of smooth teaching activities. Specifically, it constitutes the teaching scene, creates the learning psychological environment, forms the circumstances to edify students' sentiment and train the students' aesthetic feeling, providing a platform for skills training and experience.

Researchers have proposed three aspects of course resources development from the perspective of improving cultural significance:

- adapt to the changes of course organization and management;

- change the tendency of laying too much emphasis on discipline and ignoring experience;

- meet the needs of course culture construction.[1]
Some other researchers have also proposed the two functions of course resource system with respect to course activities from the perspective of system theory analysis:

- reserve function of material and conception contents of curriculum resources on human culture;

- support function of course resources for course activities.[2]

Teacher professional virtue and excellent course resources are the natural sources to form systematic material of the course, having a unique value on students' all-round development, and the important factor to determine whether or not the course objective will be realized. Make a reasonable use of the existing course resources and actively develop new course resources, is an important way to enhance teachers' professional virtue, deepen teaching reform, and improve teaching efficiency.

\section{TEACHING PROFESSION RESPECTS LIFE HARMONY IN TEACHING}

Teaching profession shall pay attention to the harmonious development of human. K. Jaspers said that: "Education is the exchange activity of body and soul among people, including the teaching of knowledge content, understanding of life connotation, regulation of volition behavior, and pass the cultural heritage on to the younger generation through the function of cultural transmission, making them generate freely and start their freedom nature." Human have the dual existence of natural life and value life. And education is not separable whether for the development improvement of natural life, or the growth of spiritual life. Education is the existence form of human life. Just as the philosopher I. Kant said, "Human is the only creature who must accept education. Human can only become a human when he has received education." Receiving education is a kind of development needs of human life and living, not the external force imposed on human themselves.

In the wave of economic development of China, education was once considered as the superstructure of social development and the productivity, to cultivate the talents required by politics and economy. In the latter half of the 20th century, education has transformed from cultivating human's external attributes to the human being themselves. In the 1970s, "double-base" was stressed, because "knowledge is power"; "ability" was emphasized in the 80s, because facing the strong challenges of science and technology revolution, "ability is more important than knowledge"; "emotion" was highlighted in the 90s, because in the technological age, only rational education losses "the other half education". The Kindergarten Education Guidelines (Trail) and Basic Education Course Guidelines (Trail) issued at the beginning of the new century have break out the partial attention of human, and point out that education should meet the needs of the children's development in various aspects, to promote their harmonious development. From concerning the society, acting as the tool to serve the society, to concerning human and acting as conscious needs for human's development; from paying attention to the single development of knowledge, ability and emotion to focusing on the overall development of human's 
body and mind, education continuously realizes the return of life. ${ }^{[3]}$

\section{VI.CONCLUSION}

The phalanx that walks in step will never produce the record-breaking champion; headless goose group can never rush out of the clouds; there will be no great trees without the buds. In the new century, teaching profession shall give play to their intelligence, creativity, and respect the personality display and harmonious development. The teacher professional virtue is developing with the times and the human, having farreaching significance for the rational development of course resources, teaching promotion and students' harmonious development.

\section{REFERENCES}

[1] "Pedagogy Foundation" jointly compiled by the national 12 key normal universities in July 2002, the first edition.

[2] Wang Taifeng. Curriculum Resources Development and Teaching Innovation, published in Journal of Teaching and Management (Taiyuan), 2004 (10).

[3] "Pedagogy Foundation" jointly compiled by the national 12 key normal universities in July 2002, the first edition.

[4] Shen Renhong, Huangfu Quan. Course Resources of Learning: Value reconstruction of Course Resources, published in Course, Teaching Material and Teaching Method (Beijing), 2004 (7).

[5] Huang Xiaoling. Course Resources: Definition, Characteristics, Status, Type, published in Chinese Journal of Education (Beijing), 2004 (4) B.

[6] Fan Zhaoxiong. System Analysis of Curriculum Resource, published in Journal of Northwest Normal University (Social Science Edition), 2002 (3).

[7] Feng Jianjun. Life and Education, Science and Education Press, November 2004, the first edition 